\title{
Editorial
}

\section{Why is Ageism a Serious Social Problem and What Can Be Done about It?}

The article by G.J. Chipperfield and Betty Havens presented in this issue highlights the problem of ageism. Ageism, that is, negative and prejudicial attitudes towards older persons which are based on stereotypes, is both an important and difficult problem for the field of aging and for society as a whole. It is an important problem because it significantly affects many current and future older persons. Further, it is a difficult problem because ageism often manifests itself in subtle ways.

As Chipperfield and Havens point out, there is an important relationship between perceived respect and self-respect. While it is true that some older people will not be severely influenced by the ageist attitudes and behaviour of others, for many people it can be a source of lowered self-respect and loss of personal meaning. This, in turn, results in decreased quality of life and well-being.

The origin of the problem of ageism is found in the fact that human beings are not isolated from each other. We all find ourselves in a world with other people. In other words, to be a human being is to be an interpersonal being. We make choices as to how we will think of ourselves, but those choices are made in a situation that is partly personal and partly social. Thus, the images or metaphors of aging (Kenyon, Birren, \& Schroots, 1991) that we construct inside ourselves are influenced by the metaphors of aging that exist outside in the social structure.

It is at this point that ageism becomes a crucial issue, due to the fact that many older people accept these negative metaphors of aging that are imposed from the outside, even though their inner image or personal metaphor does not necessarily correspond to the outer image. As M. Philibert $(1968$, p. 302) notes, the older person may know that the ageist images are questionable, that is, "Certes elles les croient provisoires et révocables, mais elles doivent les accepter pour vivre et pour agir". Older persons often resign themselves to ageist attitudes, and the price may be high both individually and in terms of the loss of potential societal contributions by a significant sector of our population.

It is interesting to note that ageist attitudes not only apply to and affect persons who are 65 years of age and older. For example, in the workplace one can experience prejudice on the basis of age much earlier. It is an accepted fact that many people who seek employment at age 40 encounter difficulties. These difficulties are often due to an interaction with younger employers who hold ageist attitudes and, in addition, are ambivalent about their own aging.

We can look to medicine for another significant source of ageism in our 
society. Many negative attitudes and improper assumptions about ability and level of health are held and made commonly by practitioners (Davidson, 1991; Lebel, 1991). The root of this problem is ageism, which can be understood here as negative unreflected attitudes and damaging implicit metaphors of aging.

The idea of implicit metaphors highlights, on the one hand, the subtlety of ageist attitudes, and, on the other hand, the difficulty associated with the effort to counter ageism. Prejudice against the elderly (and the not yet elderly) is most often not a reflected position. Such is the nature of any form of discrimination; it has an automaticity to it, coupled with a band-wagon effect. This means that ageism begins as a stereotype in the minds of an individual or a group, for whatever reasons, and then can become explicit in the form of social policies that preclude or exclude people who either are, or appear to be a particular chronological age. In this way, ageism expresses itself in the form of mandatory retirement and the distribution of health care resources based on age.

All the above constitute examples of negative external conditions which facilitate the internalization of restrictive or negative personal metaphors by older persons. These ageist-based conditions marginalize older people and make it more difficult for them to follow their preferred itinerary in life. It is evident that dialogue and research on the problem of ageism is necessary at the individual and societal level in a civilized society that is ostensibly based on humanist values and ethical principles.

Thus far it has been indicated that ageism is both a difficult and crucial issue for both individuals and society, and in particular, a rapidly aging society such as Canada. However, it is not sufficient in this case to simply point to and analyse a problem, it is also necessary to discuss possible solutions. In this regard, there are three general guidelines that can assist in the effort to counter ageism. These guidelines, as Lebel (1991) notes in discussing the medical profession, require considerable patience and often do not produce immediate results; nevertheless, they are instructive and provide a basis for further research and action.

First, current knowledge should engender caution with regard to subscribing to ageist-based claims of later life function, such as "all older people are ' $X$ '," "all older people decline," or "all older people continue to grow". The main problem with subscribing to such blanket statements is not with the claim that such things as growth and decline occur, but with the exclusive disjunction that only growth or decline marks later life function. When such claims are afforded universal status, they often lead to well-intentioned but misguided attempts to ensure that everyone conforms to a particular model or set of characteristics. What is required here is a critical evaluation of the knowledge base employed in guiding intervention decisions. Such an end is facilitated by a broad exposure to the multiple orientations and dimensions involved in the study of aging, as well as an appreciation for the complexity and interdisciplinary nature of that knowledge base. In other words, as Aristotle would say, we must get closer to the individual. Education at all levels, 
both formal and informal, and policies to support such education is a powerful and undeveloped tool for countering ageism.

However, various forms of education are not enough on their own. The second guideline is that practitioners, researchers, and broadly speaking, all people in an aging society need to be sensitive to their own assumptions and metaphors of aging. We need to develop more approaches that help to make implicit metaphors explicit. Programs and interventions that create a situation in which practitioners and policy-makers are exposed to, and interact with older people are required. In this way, professionals and others can trade-in and trade-up their personal metaphors of aging (Birren, 1987), which will then mean that they will perceive aging and older persons in a more appropriate manner. But more importantly, they will perceive the other person's metaphors and not their own projections. They will understand better the meaning of aging as it is from the inside of another person. It is one thing to have more accurate knowledge of aging and another to act and apply that knowledge in specific interactions with older people. Ageism can be countered only by knowledge and appropriate action; moreover, the second part is more difficult to achieve. It is difficult because changing one's professional and personal perceptions takes time and effort. In addition, there is the problem of dealing with the earlier discussed ambivalence that many interveners have towards even talking about their own aging and what it is to be older. Consequently, we must have the desire or intention to enter this dialogue.

The third guideline for countering ageism consists of a focus on older persons as persons. This means that much can be accomplished by a move away from the focus on age itself, and towards an emphasis on what a particular older person cannot do, and more importantly, what they can do (Davidson, 1991). This point applies in all contexts including medicine, education, the workplace and the family. The suggestion that it is important to treat older persons as persons is easier said than done, to be sure. It requires more effort and time to attempt to understand an older person as an individual, with a unique past, present and future, whether frail or healthy.

The guidelines suggested here also put pressure on the social system, and on resources available in that system. Yet, our knowledge of aging tells us that we become increasingly individualized as we age, and that therefore interacting with older people on the basis of ageist or other generalized positions is inappropriate. In fact, ageism is untenable both because it advocates a universal image of being older, and because that universal image is negative. For example, ageism leaves out any consideration of such things as personal meaning and spirituality as integral aspects of human nature. In this regard, we may ask the question as to the meaning of being older in an ageist society. In addition to what knowledge of aging tells us, there is also an ethical imperative operating here. That is, ethics tells us that all people should be treated as autonomous beings with basic rights. This is part of what it means to be a person, regardless of age, level of health, income, and so on.

Two final points are in order. First, practitioners, as people who are in- 
volved with the lives of older persons in a direct way, are in a privileged position to counter ageism and its negative effects. The practitioner or intervener plays an essential role in communicating metaphors of hope, dignity and meaning to people who are often in a vulnerable position. Further, those who do so find it to be a very fulfilling experience for all concerned.

The second and final point is a qualification of the above optimistic view. The movement from an ageist society to an age-irrelevant one (Neugarten \& Hagestad, 1976), a society in which there would be more flexibility between personal (inner) and social (outer) metaphors of aging and where older people would have more choices, presupposes the co-operation of those responsible for social and institutional policy. A postindustrial society such as Canada contains many elements of social management of human life. The individual older person can only do so much to counter ageism and the same can be said in support of practitioners. There are structural constraints in an ageist society that require efforts to be made at all levels of government; efforts that will facilitate not ageism, and not the accommodation, but the integration of older people in Canadian society.

\section{References}

Birren, J. (1987). The Best of All Stories. Psychology Today, May, 74-75.

Davidson, W. (1991). Metaphors of Health and Aging: Geriatrics as Metaphor. In G. Kenyon, J. Birren, \& J.J.F. Schroots (Eds.), Metaphors of Aging in Science and the Humanities (pp. 173-184). New York: Springer.

Kenyon, G., Birren, J., \& Schroots, J.J.F. (Eds.). (1991). Metaphors of Aging in Science and the Humanities. New York: Springer.

Lebel, P. (1991). Editorial: Does the Training in Geriatrics Affect a Doctor's Decision to Care for the Elderly? Canadian Journal on Aging, 10(3), 207-211.

Neugarten, B., \& Hagestad, G. (1976). Age and the Life Course. In R. Binstock \& E. Shanas (Eds.), Handbook of Aging and the Social Sciences (pp. 35-55). New York: Van Nostrand Reinhold.

Philibert, M. (1968). L'Échelle des Âges. Paris: Éditions du Seuil.

Gary M. Kenyon 